\title{
Vitamin E Reduces Symptoms in a CFA-induced Model of Monoarthritis
}

\author{
Department of Anesthesiology and Pain Medicine, Hospital of Konkuk University, Chungju, Korea \\ Kyu-Chang Lee, M.D., Kyong-Hwan Moon, M.D., Dae-Ki Kim, M.D., \\ Keun-Sang Lee, M.D., Nam-Sik Woo, M.D., and Ye-Chul Lee, M.D.
}

\begin{abstract}
Background: Adjuvant arthritic animals show immunologic and inflammatory features which are also observed in patients with rheumatoid arthritis. This study investigated whether high dose vitamin E (a-tocopherol) has any additional anti-inflammatory or analgesic effects, or both, in Complete Freund's adjuvant (CFA) induced arthritic rat model.

Methods: Male Sprague-Dawley rats $(300-350 \mathrm{~g}, \mathrm{n}=3)$ underwent testing up to 26 days after induction of the model. Vitamin E (100 mg/kg) or vehicle was given daily intraperitoneally (IP) for 10 or 20 days following induction. Thus, groups were as follows: group 1 , untreated, $\mathrm{n}=3$; group 2 , CFA + vehicle, $\mathrm{n}=10$; group 3 , CFA + vitamin $\mathrm{E}$ for 10 days, $\mathrm{n}=$ 10; group 4, CFA + vitamin $\mathrm{E}$ for 20 days, $\mathrm{n}=10$. Parameters compared between groups included ankle circumference, range of articulation of the arthritic joint, extravasation of plasma proteins in the tissues around the arthritic joint and sensory withdrawal threshold to von Frey filament mechanical stimulation.

Results: Compared to CFA rats administered drug vehicle, those given vitamin E for 20 days exhibited a reduction in all symptoms of monoarthritis, including less ipsilateral ankle swelling, reduced loss of the range of joint articulation, low plasma extravasation and reversal of the decrease in sensory withdrawal threshold. But, vitamin E for 10 days has only analgesic effect until 10 days.

Conclusions: This study showed relatively long duration of high-dose vitamin E treatment have anti-inflammatory and early onset analgesic effects. The findings raise the possibility of high dose vitamin E, or potentially other antioxidants, as adjuvant therapy for alleviation of symptoms of rheumatoid arthritis. (Korean J Anesthesiol 2006; 50: S 61 7)
\end{abstract}

Key Words: anti-inflammatory effect, complete Freund's adjuvant, high dose vitamin E, pain measurement.

\section{INTRODUCTION}

Rheumatoid arthritis (RA) is a chronic disease affecting up to $3 \%$ of the population in most countries. The causes of RA have not been completely elucidated. Oxygen free radicals have been implicated as mediators of tissue damage in patients with RA. Thus it is possible that several micronutrients acting as antioxidants and free radical scavengers provide protection against RA.

The generation of reactive oxygen species (free radicals) ${ }^{1,2)}$ is an important factor in the development and maintenance of

Received : September 20, 2005

Corresponding to : Kyu-Chang Lee, Department of Anesthesiology and Pain Medicine, Hospital of Konkuk University, 620-5 Gyohyeon 2dong, Chungju-si, Chungbuk 380-704, Korea. Tel: 82-43-840-8321, Fax: 82-43-843-9251, E-mail: leekyu@kku.ac.kr

This work was supported by the Konkuk University.
RA in humans and animal models. One source of free radicals is nitric oxide produced within the synoviocytes and chondrocytes and giving rise to the highly toxic radical peroxynitrite. Several cytokines, including tumor necrosis factor-alpha (TNFalpha) are involved in the formation of free radicals, partly by increasing the activity of nitric oxide synthase. Free radicals contribute significantly in modification of immune processes and inflammatory reactions. They are produced by activated phagocytes, which for killing microorganisms.

Free radicals facilitate production of cytokines, which are important as modifiers of inflammatory reactions. Formation of free radicals is influenced by antioxidants, which thus modify the intensity of inflammatory reaction and immune response. The antioxidant defenses consist of low molecular mass antioxidants such as vitamins $\mathrm{C}$ and $\mathrm{E}$ and enzymes, e.g. superoxide dismutase. Their function is to act as a coordinated and balanced system to protect tissues and body fluids from damage by reactive oxygen whether produced physiologically 
or as a response to inflammation, infection or disease. The plasma concentration of the principal lipophilic antioxidant, alpha-tocopherol, is lower in patients with rheumatoid arthritis than in healthy age- matched controls, although this association may be a result of the disease or its treatment. ${ }^{3)}$ Similarly, a cohort study identified low alpha-tocopherol status as a risk factor for rheumatoid arthritis. ${ }^{4)}$ When supplemental alpha-tocopherol was administered orally to rheumatoid arthritis patients who were already receiving anti-rheumatic drugs, three measures of pain (i.e., pain in the morning, pain in the evening, and pain after chosen activity) were decreased compared to placebo control. ${ }^{5)}$ Therefore, the aim of the present study was to assess the therapeutic value of daily injection of vitamin $\mathrm{E}$ in an animal model of arthritis.

\section{MATERIALS AND METHODS}

\section{Animals}

Experiments were conducted on male Sprague-Dawley rats weighing between 300-350 grams. The rats were housed in pairs, and maintained on a 12/12 hour allowed free access to food and water. All experiments were preformed according to approved protocol by the animal care committee at the University of Western Ontario, in accordance with the guidelines from the Canadian Council of Animal Care and I.A.S.P Committee for Research and Ethical Issues.

Vitamin E $(100 \mathrm{mg} / \mathrm{kg})$ or vehicle was given daily intraperitoneally (IP) for 10 or 20 days following induction.

Thus, groups were as follows: group 1 , untreated, $\mathrm{n}=3$; group 2, $\mathrm{CFA}+$ vehicle, $\mathrm{n}=10$; group $3, \mathrm{CFA}+$ vitamin $\mathrm{E}$ for 10 days, $\mathrm{n}=10$; group $4, \mathrm{CFA}+$ vitamin $\mathrm{E}$ for 20 days, $\mathrm{n}=10$.

\section{Induction of mono-arthritis ${ }^{6}$}

For the formal studies of the final model the complete Freund's adjuvant (CFA) was prepared as follows: $60 \mathrm{mg}$ of killed Mycobacterium butyricum (Difco laboratories) were added to a mixture of mineral oil $6 \mathrm{ml}$, saline $4 \mathrm{ml}$, and Tween $80 \mathrm{ml}$ mixed thoroughly and then autoclaved for 20 min at $120^{\circ} \mathrm{C}$ to rupture the cell walls of mycobacteria. This preparation was refrigerated until use and warmed and thoroughly mixed prior to injection to prepared animals. Injection of the right hind ankle joints was performed under brief halothane $/ \mathrm{O}_{2}$ anesthesia as follows: the tarsal area of the hind paw was grasped and the fossa distal and medial to the lateral malleolus of the fibula was palpated. A 27-gauge needle was introduced into the capsule of the tibio-tarsal joint (TTJ) percutaneously by directing it cephalad, mesiad and superiorly from the midpoint of the inframalleolar fossa until a distinct loss of resistance was felt approximately $4 \mathrm{~mm}$ and complete adjuvant was injected. (135॥g of mycobacterium butyricum in $25 \mathrm{~b} \| 1$ vehicle). Baseline (pre-induction) clinical observations were made prior to injection of CFA.

\section{Vitamin E treatment}

Vitamin E was prepared as follows: vitamin E was dissolved in one volume of ethanol and then diluted with nine volumes of $16 \%(\mathrm{v} / \mathrm{v})$ Tween 80 in saline. Rats were injected via IP daily with either vitamin $\mathrm{E}(100 \mathrm{mg} / \mathrm{kg})$ or vehicle. ${ }^{7)} \mathrm{G} 1$ was untreated control group; G2 was injected with CFA and administered vehicle for vitamin E; group G3 was injected with CFA and received vitamin E for 10 days while G4 was injected with CFA and vitamin $\mathrm{E}$ for 20 days. Vehicle or vitamin $\mathrm{E}$ treatment started on one day after CFA injection. All injections were given around 10:00 o'clock in the morning before testing began. Some parameters were continued to measure for 2 to 3 days after stopping the administration of vitamin $\mathrm{E}$ to see if the effect continued to persist.

\section{Clinical experiments}

Ankle circumference: The animal was acclimatized to a piece of cloth that was wrapped around it to minimize movement and to reduce handling stress. A piece of thread was wrapped around the ipsilateral ankle joint and the length of thread around the joint was determined. This procedure was repeated three times and the values averaged. Measurements were taken daily or according to the experiment protocol.

Range of articulation: The degree of articulation for the ipsilateral ankle joint was determined as follows. The axis of the femoral bone and the heel of the foot were set as the reference points. The tarsal bone was flexed and extended to the maximum and the reading taken. Range of articulation was determined as the difference between the angle of maximum extension and the angle of maximum flexion.

Mechanical withdrawal threshold (von Frey hair): Mechanical response thresholds were determined by measuring the hind paw withdrawal response to Von Frey filament stimulation according to the method described by Pitcher. ${ }^{8)}$ In brief, animals were placed in a Plexiglas ${ }^{\circledR}$ box $(30 \times 30 \times 30$ $\mathrm{cm})$ with an opaque plastic floor $(3 \mathrm{~mm}$ thick with $1.5 \mathrm{~mm}$ 
diameter holes in perpendicular holes $5 \mathrm{~mm}$ apart) through witch the von Frey filaments (Stoelting) were applied to the soft tissue of the plantar surface of the injured hind paw. Filaments were applied in ascending order, beginning at 0.25 $\mathrm{g}$, to determine the filament closest to the threshold of response. Each filament was applied to the hind paw 5 times for $2 \mathrm{sec}$ at 10 -second intervals. A withdrawal response was considered if the hind paw was completely removed from the surface of the platform. The withdrawal response was recorded for the filament that successfully stimulated withdrawal $4 / 5$ or $5 / 5$ times. The gram force of each hair was determined at the end of each testing period. ${ }^{9)}$

\section{Physiological experiments}

Plasma extravasation and edema measurement: Plasma extravasation measurement was accomplished on day 26 under anesthetzed. Initially, animals were anesthetized with sodium pentobarbital at a dose of $50 \mathrm{mg} / \mathrm{kg}$. Evans blue Dye, 25 $\mathrm{mg} / \mathrm{ml}$ saline, was injected via the tail vein at $0.1 \%$ body weight (gm). Thirty minutes after the injection of Evans blue dye, $500 \mathrm{ml}$ of saline was perfused through the aorta. Subsequently a measured length of the paw close to the ankle was removed and weighed to obtain the wet weight of the tissues. It was then dried in an oven at $60^{\circ} \mathrm{C}$ and after 24 hours the weight of the dried tissue was obtained. The difference between the wet and dry weights was measured as edema. The dried tissue was then placed in a vial with $10 \mathrm{ml}$ of formamide in an oven at $60^{\circ} \mathrm{C}$. Twenty four hours later, the fluid in the vials was filtered and evaluated by its absorbance measure by color spectrophotometer compared to pure formamide at wavelength $600 \mathrm{~nm}$. Calculated formula is ([ipsilateral absorbance/ipsilateral weight]/[contralateral absorbance/contralateral weight]).

Statistical analysis: Statistical analysis was done using either the students unpaired t-test or one way analysis of variance (ANOVA) $\mathrm{P}<0.05$ was considered statistically significant for all analysis. All data are expressed as means \pm SEM.

\section{RESULTS}

The adjuvant-induced arthritis model has been used for evaluation of compounds with potential for treatment of human RA, and the development of ankle edema is commonly used as a measure of inflammation. ${ }^{10)}$ Another symptom commonly seen in potential is lack of flexibility of the joint. Thus ankle circumference and flexibility were used as a measure to study the effect of vitamin E treatment in model of monoarthritis.

\section{Ankle circumference}

The mean baseline circumference of ankle in a normal animal was observed to be $28.9 \pm 0.07 \mathrm{~mm}$. After the induction of arthritis the ankle circumference started to increase on second day and the mean value recorded was $38.2 \pm 0.6$ $\mathrm{mm}$ on day 2. Daily injection of vitamin E for 10 days to the monoarthritis rat did not affect the increase of ankle circumference. But a significant decrease was observed when a daily injection of vitamin $\mathrm{E}$ was given for 20 days compared to CFA animals treated with vehicle only ( $\mathrm{n}=7, \mathrm{P}<0.05$ ). This decreases remained up to 23 days even when the daily dose of vitamin E was stopped on day 20 (Fig. 1).

\section{Range of articulation of the joint}

As shown in Fig. 2, the range of articulation of the tibiotarsal joint of the CFA animals deteriorated with time. Daily injection of vitamin $\mathrm{E}$ to CFA animals $(\mathrm{n}=7)$ for 10 days did not alter this deterioration significantly. However, treatment with vitamin $\mathrm{E}$ for 20 days was so effective that the range of articulation remained almost normal. Thus a significant difference $(\mathrm{P}<0.05)$ arose between the CFA rats that received vitamin $\mathrm{E}(\mathrm{n}=7)$ and those that received was observed

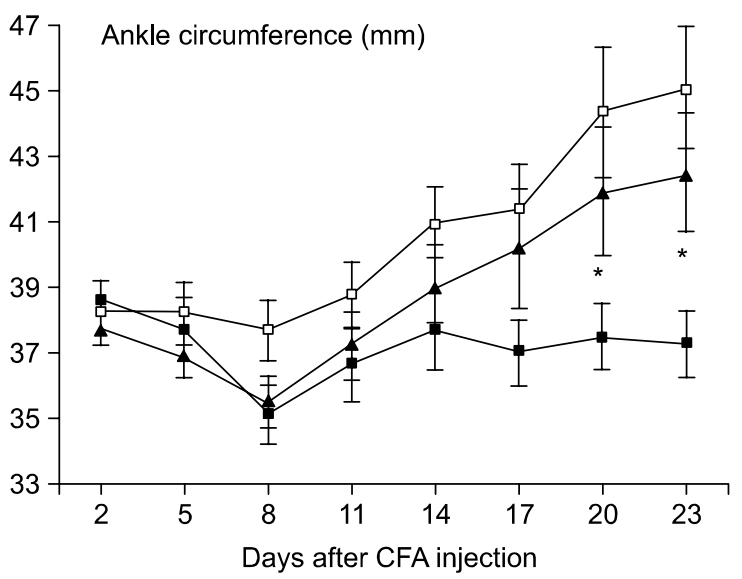

Fig. 1. Effect of vitamin $\mathrm{E}$ on circumference of ipsilateral ankle joint of monoarthritic rats. Significant difference started on day 18 between CFA group given vehicle $(\square, \mathrm{n}=7)$ and CFA group given vitamin $\mathrm{E}$ for 20 days $(\boldsymbol{\square}, \mathrm{n}=7, \mathrm{P}<0.05)$. No significant difference was observed between vehicle and the group given 10 days of vitamin $\mathrm{E}$ $(\boldsymbol{\Delta}, \mathrm{n}=7) .{ }^{*} \mathrm{P}<0.05$. 
vehicle $(\mathrm{n}=7)$.

\section{Mechanical withdrawal threshold}

Sensory withdrawal thresholds to mechanical stimulation in

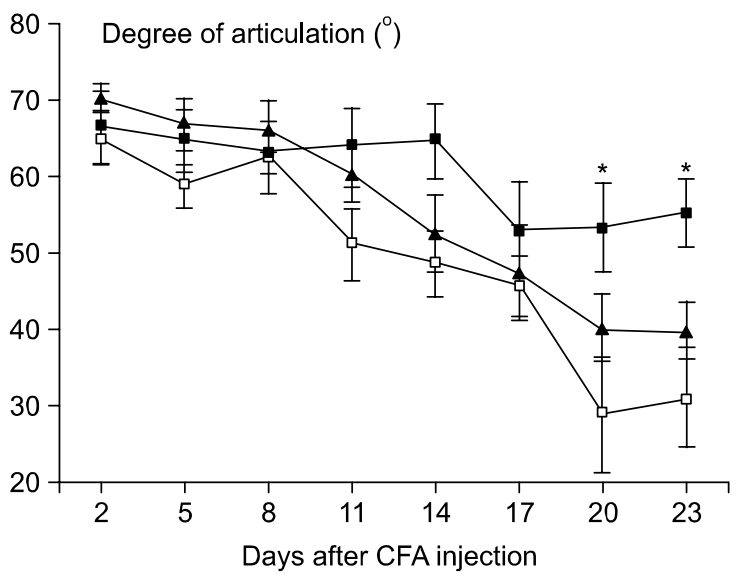

Fig. 2. Range of articulation of tibio-tarsal joint in monoarthritic rats with vitamin E. Daily injection of vitamin E for 20 days $(\boldsymbol{\square}, \mathrm{n}=7)$ prevented the decrease in articulation of the joint which became significant on day 20 when compared to the group of CFA rats with vehicle $(\square, \mathrm{n}=7, \mathrm{P}<0.05)$. Daily injection of vitamin $\mathrm{E}$ for 10 days had no effect on the articulation of the joint $(\boldsymbol{\Delta}, \mathrm{n}=7)$. ${ }^{*} \mathrm{P}<$ 0.05 .

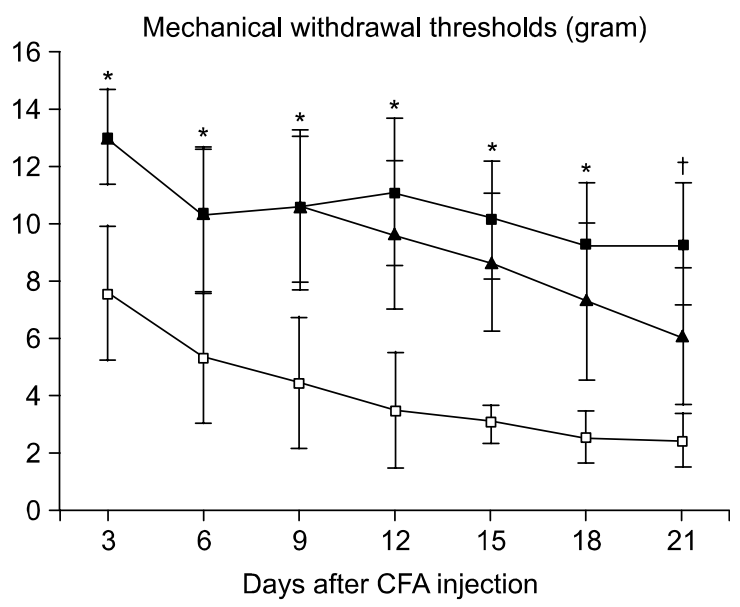

Fig. 3. Effect of vitamin $\mathrm{E}$ on sensory threshold to mechanical stimulation in monoarthritic rats. A daily dose of vitamin $\mathrm{E}$ for 20 days to CFA treated rats $(\boldsymbol{\square}, \mathrm{n}=7)$ prevented the decrease in sensitivity to mechanical stimulation as compared to CFA group with vehicle ( $\square$, $\mathrm{n}=7$ ). The difference was first significant on day 3 and remained significant up to the end of observation period on day 21 ( $\mathrm{P}<0.01$ ). A daily dose of vitamin $\mathrm{E}$ for 10 days $(\boldsymbol{\Delta}, \mathrm{n}=7)$ was significantly different from the control group. ${ }^{\star} \mathrm{P}<0.05,{ }^{\dagger} \mathrm{P}<0.01$. ipsilateral ankle joint with vitamin $\mathrm{E}$ treatment started to show an analgesic effect as early as on day 3 after CFA injection ( $\mathrm{P}<0.05$ on 20-day vitamin $\mathrm{E}$ treatment as compared to vehicle, Fig. 3). The baseline value of withdrawal threshold before induction of monoarthritis in normal rats was $15 \pm 0$. As Fig. 3 shows the group of CFA animals given vehicle only demonstrated a gradual increase in mechanical sensitivity that was indicated by a change in the withdrawal threshold as early as on day 3 after CFA injection $(7.7 \pm 2.1$ on day 3 and 2.4 \pm 0.9 on day 21). This sensitivity to the mechanical stimulation was prevented by a daily administration of vitamin $\mathrm{E}$ in both 10 days and 20 days groups (threshold values averaged $9.3 \pm 2.1$ on day $18, \mathrm{n}=6, \mathrm{P}<0.05$ as compared to vehicle). The group with 10 days administration of vitamin E (group 3) showed delayed lowering of the mechanical withdrawal thresholds until 10 days. There was no statistical significance between group 3 and group 4 .

\section{Plasma extravasation}

Compared to the control group of rats, CFA treated rats showed significantly greater plasma extravasation $(\mathrm{n}=6, \mathrm{P}<$ 0.05 , Fig. 4). However, a daily injection of high dose of vitamin $\mathrm{E}$ for 20 days reduced the permeability of the vasculature surrounding the tibio-tarsal joint, significantly when

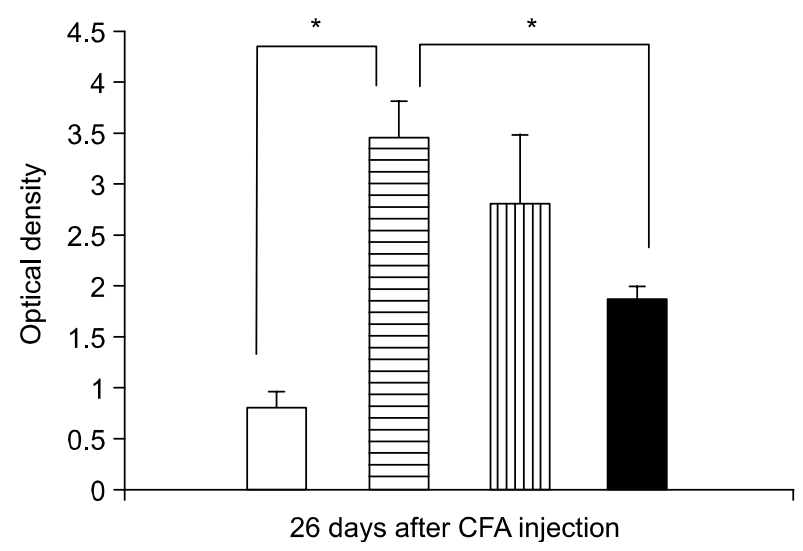

Fig. 4. Effect of vitamin $\mathrm{E}$ on extravasation of plasma proteins around the tibio-tarsal joint of CFA treated rats. Significant difference in the values of plasma extravasation was observed in CFA rats (目, $\mathrm{n}=6$ ) compared to the normal untreated rats $(\square, \mathrm{n}=3, \mathrm{P}<0.01)$. The difference between these groups was significant $(P<0.01)$, when vitamin $\mathrm{E}$ was administered for 20 days $(\boldsymbol{\square}, \mathrm{n}=6)$. Extravasation of plasma proteins was seen to be much less compared to the vehicle treated group. A daily injection of vitamin $\mathrm{E}$ for 10 days, to the CFA rats $(\mathbb{W}, \mathrm{n}=5)$ showed a slight decrease but not significant as compared to the vehicle treated rats. ${ }^{*} \mathrm{P}<0.01$. 


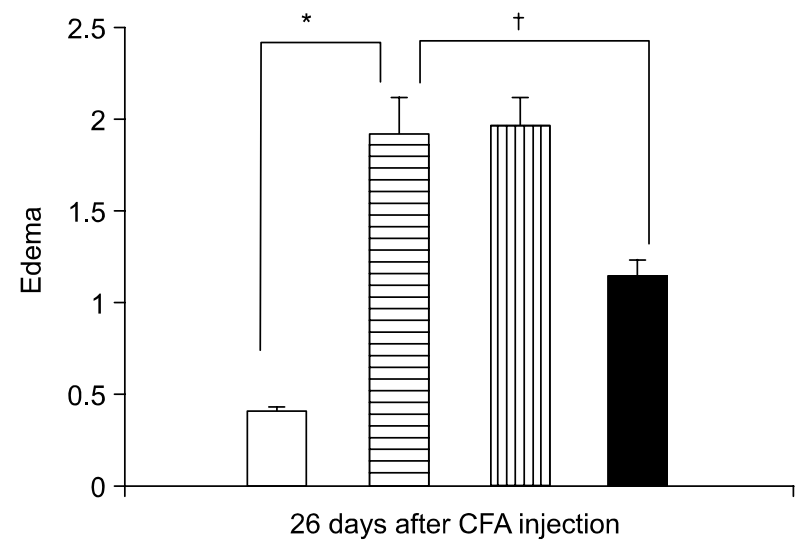

Fig. 5. Edema in the tibio-tarsal joint of monoarthritic rats (目, $n$ = 6) was significantly higher than the untreated controls $(\square, \mathrm{n}=$ $3, \mathrm{P}<0.01)$. Administration of vitamin $\mathrm{E}$ for 10 days to CFA treated rats $(\mathbb{W}, \mathrm{n}=5$ ) showed no improvement but vitamin $\mathrm{E}$ injected daily for 20 days $(\boldsymbol{\square}, \mathrm{n}=6)$ had a significant effect on reducing the edema of the arthritic joint $(\mathrm{P}<0.05)$ compared to the vehicle treated rats. ${ }^{*} \mathrm{P}<0.01,{ }^{\dagger} \mathrm{P}<0.05$.

compared to vehicle treated arthritic rats $(\mathrm{n}=6, \mathrm{P}<0.01$, Fig. 4). No effect was seen when vitamin $\mathrm{E}$ was given for only for 10 days.

\section{Edema}

The effect of vitamin $\mathrm{E}$ on edema induced by CFA is shown in the Fig. 5. Compared to the control rats $(n=3)$, edema was significantly greater in CFA animals $(\mathrm{n}=6, \mathrm{P}<$ 0.001). Vitamin $\mathrm{E}$ administration for 10 days did not affect edema in CFA rats $(n=5)$. However, the 20 days treatment with vitamin $\mathrm{E}$ decreased edema compared to vehicle control $(\mathrm{n}=7, \mathrm{P}<0.05)$.

\section{DISCUSSION}

This study was aimed to investigate whether high dose vitamin $\mathrm{E}$ has any anti-inflammatory or analgesic effects or both in CFA induced arthritic rat model. Adjuvant-induced arthritis in rats is widely used as a model of human RA because adjuvant arthritic animals show immunologic and inflammatory features which are also observed in patients with RA. $^{10)}$ The CFA-induced inflammation resulted in significant elevation in the levels of TNF-alpha, IL-1 beta and nerve growth factor (NGF) in the inflamed paw and the peptides, substance $\mathrm{P}$ and calcitonin gene-related peptide (CGRP) in the L4 dorsal root ganglion $48 \mathrm{~h}$ post CFA injection. ${ }^{11)}$ The activation of nitric oxide synthase (NOS) can be induced by lipopolysaccharide (LPS) and several cytokines such as inter-

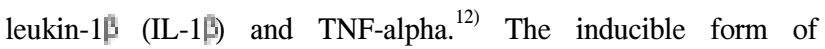
the synthetic enzyme nitric oxide synthetase (iNOS) is found primarily in synovial lining layer (especially CD68+ macrophages and fibroblasts and type A synoviocytes), chondrocytes and epithelial cells. ${ }^{13)}$

Joint pain is a common symptom in various forms of arthritis. Unfortunately, the mechanisms involved in the pathogenesis of joint pain are not well understood, but probably include peripheral and central neural mechanisms.

Noxious stimulation leads to the release of aspartate, glutamate and substance $\mathrm{P}$ in the dorsal horn of the spinal cord. Activity of these transmitters at N-Methyl-D-Aspartate (NMDA), NK-1 and metabotropic glutamic receptors result in increased intracellular $\mathrm{Ca}^{2+}$ in dorsal horn cells. The increase in intracellular $\mathrm{Ca}^{2+}$ stimulates the nitric oxide synthaseinduced conversion of L-arginine to nitric oxide and the phospholipaseA2-induced release of arachidonic acid. Lastly, central sensitization in the spinal cord may play an important role in the pathogenesis of joint pain. Phosphorylation of the NMDA receptor by activated kinases allows the NMDA receptor to operate at resting membrane potential level and further enhances the accumulation of intracellular $\mathrm{Ca}^{2+}$. Synthesis of novel transmitters, growth factors and ion channels may lead to phenotypic changes within the nociceptive system (e.g. production of substance $\mathrm{P}$ in large fibers). ${ }^{14)}$ Vitamin $\mathrm{E}$ is the major lipid soluble antioxidant found in human plasma, erythrocytes, and tissues. ${ }^{15)}$ The efficacy of vitamin $\mathrm{E}$ has been studied in a variety of rheumatological disorders including RA, osteoarthritis, and ankylosing spondylitis. ${ }^{2,8,16)}$

Our study showed significantly greater plasma extravasation and edema from group 4 . We think that means accumulation effect of high dose vitamin E. ${ }^{17)}$ Vitamin $E$ treatment of the transgenic animals led to a significant decrease in the levels of IL-1 $\beta$ but not TNF-alpha. ${ }^{2)}$ Also vitamin $\mathrm{E}$ has a peripheral anti-inflammatory effect is related to inhibition of arachidonic acid pathway, ${ }^{17)}$ or scavenging of free radicals. ${ }^{18)}$ Vitamin $\mathrm{E}$ could inhibit ROS release by neutrophils and monocytes by blocking the activity of protein kinase $\mathrm{C}$ (PKC), which is involved in the activation of NADPH oxidase. ${ }^{19)}$

Vitamin E activates microglial PP2A activity and thereby silences an LPS-activated PKC/extracellular signal regulated kinase (ERK)/Nuclear factor kappa B (NF-kB) signalling cascade resulting in significantly attenuated COX-2 protein synthe- 
sis. $^{20)} \mathrm{NF-KB}$ is an ubiquitous rapid response transcription factor in cells involved in immune and inflammatory reactions, and exerts its effect by expressing cytokines, chemokines, cell adhesion molecules, growth factors, and immunoreceptors. In this manner, NF-KB contributes to immunologically mediated diseases such as allograft rejection, RA, and bronchial asthma. ${ }^{21)}$ Vitamin $\mathrm{E}$ has effectively inhibited the activation of cytokineinduced NF-KB by influencing the redox state of the cell. Since NF-KB plays a critical role in the induction of an iNOS gene by LPS. $^{22)}$

Vitamin E was found to inhibit LPS-induced formation of PGE2 at 100-300 M, which is within the range of plasma or tissue concentrations that can be expected during high-dose oral therapy. ${ }^{23-25)}$ Inhibition of prostaglandin formation was accompanied by comparable decrease in COX-2 expression at the translational and transcriptional level. Vitamin E-induced decrease in PGE2 production is due to decreased COX activity. However, vitamin $\mathrm{E}$ had no effect on COX mRNA and protein levels, indicating a post-translational regulation of $\mathrm{COX}$ by vitamin E. Further experiments indicated that vitamin $\mathrm{E}$ decreases $\mathrm{COX}$ activity through reducing formation of peroxynitrite, a hydroperoxide shown to be involved in the ativation of COX-2 (dose dependent, peroxinitrite is important). Another study demonstrated that attenuation of the formation of 5lipoxygenase products in polymorphonuclear neutrophils (PMNL) can be achieved by dietary vitamin E enrichment. ${ }^{26)}$ Activation of PMNL leads to the release of arachidonate from cellular phospholipids via a phospholipase $\mathrm{A} 2$, and conversion of products of the 5-lipoxygenase pathway. The inhibition of PGE2 production by vitamin $\mathrm{E}$ results from the inhibition of the activities of both phospholipase A2 and cyclooxygenase. ${ }^{27}$

The present results showed analgesic effect on day 3 from group 3 and group 4. In nested case-control studies using serum obtained prior to diagnosis of rheumatoid arthritis, alpha-tocopherol concentration was inversely associated with the later development of rheumatoid arthritis. ${ }^{28)}$ When supplemental alpha-tocopherol was admininistered orally to rheumatoid arthritis patients who were already receving anti-rheumatic drugs, three measurement of pain (i.e., morning stiffness, pain in the evening, and pain after chosen activity) were decreased compared to placebo control. ${ }^{5)}$ Surprisingly, this pain relief occurred even though vitamin E did not change clinical indices of inflammation. ${ }^{3)}$ Also, vitamin $\mathrm{E}$ treatment did not modify the clinical features of the disease (date of onset or disease intensity, as measured by the articular index), but it did prevent joint destruction from transgenic mouse model of rheumatoid arthritis. ${ }^{29)}$ In conclusion this study shows relatively long duration of high dose vitamin $\mathrm{E}$ treatment have antiinflammatory and early onset analgesic effect.

\section{REFERENCES}

1. Bauerova K, Bezek A: Role of reactive oxygen and nitrogen species in etiopathogenesis of rheumatoid arthritis. Gen Physiol Biophys 1999; 18: 15-20.

2. Bandt MD, Grossin M, Driss F, Pincemail J, Babin-Chevaye C, Pasquier C: Vitamin E uncouples joint destruction and clinical inflammation in a transgenic mouse model of rheumatoid arthritis. Arthritis Rheum 2002; 46: 522-32.

3. Bae SC, Kim SJ, Sung MK. Inadequate antioxidant nutrient intake and altered plasma antioxidant status of rheumatoid arthritis patients. J Am Coll Nutr 2003; 22: 311-5.

4. Knekt P, Heliovaara M, Aho K, Alfthan G, Marniemi J, Aroma A: Serum selenium, serum alpha-tocopherol, and the risk of rheumatoid arthritis. Epidemiology 2000; 11: 402-5.

5. Edmonds SE, Winyard PG, Guo R, Kidd P, Merry P, LangrishSmith A, et al: Putative analgesic activity of repeated oral doses of vitamin $\mathrm{E}$ in the treatment of rheumatoid arthritis. Results of a prospective placebo controlled double blind trial. Ann Rheum Dis 1997; 56: 649-55.

6. Butler SH, Godefroy F, Besson JM, Weil-Fugazza J: A limited arthritic model for chronic pain studies in the rat. Pain 1992; 48: 73-81.

7. Hidiroglou M, Karpinski K: Pharmacokinetic disposition in sheep of various vitamin $\mathrm{E}$ preparations given orally or intravenously. Br J Nutr 1988; 59: 509-18.

8. Pitcher GM, Ritchie J, Henry JL: Paw withdrawal threshold in the von Frey hair test is influenced by the surface on which the rat stands. J Neurosci Methods 1999; 87: 185-93.

9. Chaplan SR, Bach FW, Pogrel JW, Chung JM, Yaksh TL: Quantitative assessment of tactile allodynia in the rat paw. J Neurosci Methods 1994; 53: 55-63.

10. Walz DT, DiMartino MJ, Misher A: Adjuvant-induced arthritis in rats. II. Drug effects on physiologic, biochemical and immunologic parameters. J Pharmacol Exp Ther 1971; 178: 223-31.

11. Safieh-Garabedian B, Poole S, Allchorne A, Winter J, Woolf CJ: Contribution of interleukin-1 beta to the inflammation-induced increase in nerve growth factor levels and inflammatory hyperalgesia. Br J Pharmacol 1995; 115: 1265-75.

12. McCann SM, Licinio J, Wong ML, Yu WH, Karanth S, Rettorri V: The nitric oxide hypothesis of aging. Exp Gerontol 1998; 33: 813-26.

13. Grabowski PS, Wright PK, Van't Hof RJ, Helfrich MH, Ohshima $\mathrm{H}$, Ralston SH: Immunolocalization of inducible nitric oxide synthase in synovium and cartilage in rheumatoid arthritis and osteoarthritis. Br J Rheumatol 1997; 36: 651-5. 
14. Dickenson AH, Sullivan AF: Evidence for a role of the NMDA receptor in the frequency dependent potentiation of deep rat dorsal horn nociceptive neurones following $\mathrm{C}$ fibre stimulation. Neuropharmacology 1987; 26: 1235-8.

15. Burton GW, Joyce A, Ingold KU: First proof that vitamin E is major lipid-soluble, chain-breaking antioxidant in human blood plasma. Lancet 1982; 2: 327.

16. Machtey I, Ouaknine L: Tocopherol in Osteoarthritis: a controlled pilot study. J Am Geriatr Soc 1978; 26: 328-30.

17. Hidiroglou By M, Karpinski K: Disposition kinetics and dosage regimen of vitamin $\mathrm{E}$ administered intramuscularly to sheep. $\mathrm{Br}$ J Nutrition 1991; 65: 465-73.

18. Reddanna P, Rao MK, Reddy CC: Inhibition of 5-lipoxygenase by vitamin E. FEBS Lett 1985; 193: 39-43.

19. Cachia O, Benna JE, Pedruzzi E, Descomps B, Gougerot-Pocidalo MA, Leger CL: Alpha-tocopherol inhibits the respiratory burst in human monocytes. Attenuation of p47 (phox) membrane translocation and phosphorylation. J Biol Chem 1998; 273: 32801-5.

20. Calfee-Mason KG, Spear BT, Glauert HP: Vitamin E inhibits hepatic NF-kappaB activation in rats administered the hepatic tumor promoter, phenobarbital. J Nutr 2002; 132: 3178-85.

21. Lee JI, Burckart GJ: Nuclear factor kappa B: important transcription factor and therapeutic target. J Clin Pharmacol 1998; 38: 981-93.

22. Hattori S, Hattori Y, Banba N, Kasai K, Shimoda S: Pentamethylhydroxychromane, vitamin $\mathrm{E}$ derivative, inhibits induction of nitric oxide synthase by bacterial lipopolysaccharide. Biochem Mol Biol Int 1995; 35: 177-83.
23. Acuff RV, Thedford SS, Hidiroglou NN, Papas AM, Odom TA Jr: Relative bioavailability of RRR- and all-rac-alpha-tocopheryl acetate in humans: studies using deuterated compounds. Am J Clin Nutr 1994; 60: 397-402.

24. Schultz M, Leist M, Petrzika M, Gassmann B, Brigelius-Flohe R: Novel urinary metabolite of alpha-tocopherol, 2,5,7,8-tetramethyl-2 (2'-carboxyethyl)-6-hydroxychroman, as an indicator of an adequate vitamin E supply? Am J Clin Nutr 1995; 62: S1527-34.

25. Wang Y, Walsh SW: Antioxidant activities and mRNA expression of superoxide dismutase, catalase, and glutathione peroxidase in normal and preeclamptic placentas. J Soc Gynecol Investig 1996; 3: $179-84$.

26. Devaraj S, Jialal I: Alpha-tocopherol decreases interleukin-1 beta release from activated human monocytes by inhibition of 5lipoxygenase. Arterioscler Thromb Vasc Biol 1999; 19: 1125-33.

27. Sakamoto W, Fujie K, Nishihira J, Mino M, Morita I, Murota S: Inhibition of PGE2 production in macrophages from vitamin Etreated rats. Prostaglandins Leukot Essent Fatty Acids 1991; 44: 89-92.

28. Comstock GW, Burke AE, Hoffman SC, Helzlsouer KJ, Bendich A, Masi AT, et al: Serum concentrations of alpha tocoperol, beta carotene, and retinal preceding the diagnosis of rheumatoid arthritis and systemic lupus erythematosus. Ann Rheum Dis 1997; 56: 323-5.

29. Bandt MD, Grossin M, Driss F, Pincemail J, Babin-Chevaye C, Pasquier C: Vitamin E uncouples joint destruction and clinical inflammation in a transgenic mouse model of rheumatoid arthritis. Arthritis Rheum 2002; 46: 522-32. 